\title{
Enterprise Modelling for Value Based Service Analysis
}

\author{
Paul Johannesson ${ }^{1}$, Birger Andersson ${ }^{1}$, Maria Bergholtz ${ }^{1}$, and Hans Weigand ${ }^{2}$ \\ ${ }^{1}$ Royal Institute of Technology \\ Department of Computer and Systems Sciences, Sweden \\ $\{$ pajo, ba, maria\} @dsv.su.se \\ ${ }^{2}$ Tilburg University, P.O. Box 90153, 5000 LE Tilburg, The Netherlands \\ H.Weigand@uvt.nl
}

\begin{abstract}
Service oriented architectures are becoming increasingly important as enablers of exchange, coordination, and cooperation between organizations and individuals. Engineering and management of services raise a number of issues concerning the analysis, design, integration, bundling, and maintenance of services. These issues are notoriously difficult to resolve due to the abstractness of services as compared to other kinds of resources. In this paper, we analyze the concept of service based on a number of definitions from the literature and propose a conceptual service model based on the REA ontology. The model relates the service notion to the resource concept and shows how the abstractions offered by services can be represented using an encapsulation relationship. The use of the proposed service model is illustrated by means of an application on marketing oriented representation and design of services.
\end{abstract}

\section{Introduction}

Enterprise Modelling is the practice of describing a business enterprise with the dual purposes of maintaining a fit between on the one hand, the enterprise and its IT resources, and on the other hand, the enterprise and its business context. To maintain the fit between the enterprise and its business context methods and frameworks have been developed that typically include notions such as goals, means, and strategies, e.g., [1, 2, 3]. To maintain the fit between the enterprise and its IT resources, a rich body of research stretching from the 80's and onwards is available. This research has mainly focused on information and information systems modelling, together with related methodologies, and on enterprise architectures, e.g., [4, 5, 6].

In recent years the notion of "service" has gained in interest. It was originally conceived as a convenient abstraction for thinking about legacy and other IT-resources within an enterprise, but its scope has widened [7]. According to [8] service science refers to the modeling of service systems and their life cycles ranging from business components and business models to value networks of businesses linked globally. Service engineering is about the design, development, deployment, operations and maintenance of service systems based on IT, knowledge workers and outsourced business components.

The service abstraction has proved useful for the purpose of modelling IT resources of an enterprise, but is, in the context of enterprise modeling, not as commonly used as a 
business concept. One reason may be the vagueness and abstractness of the concept of service, stemming from many differing and conflicting definitions $[9,10,11,12,13$, $14,15]$. Common is that the concept of service is defined from a technical standpoint and then often in SOA terms $[16,17]$. We agree with $[8,18]$ in that the technical standpoint is but one aspect of the concept, and when discussing collaborations leading to resource distribution among economic agents we claim it is not even the most important one. In this context, the concept of service should be explained in social and economic terms.

We believe that enterprise modeling can be an effective instrument for clarifying the service concept and the main purpose of this paper is to propose a conceptual service model. The starting point of this model is not software services, but services that provide value to customers at the business level and that can be offered in an economically viable way. We, therefore, use value oriented notions as the basis of the service model, in particular the REA ontology. Furthermore, we illustrate the use of the proposed service model by showing how it can be applied for describing and designing services from a marketing oriented perspective. The benefit of this work is that services are explained and justified in terms of marketing notions, such as needs, benefits, and transfers of value. Those are notions that are closely aligned with the concepts of business collaborations, and service models of such collaborations become more stable as a result.

The remainder of this paper is structured as follows. In section 2, we recapture the REA ontology that we use in section 3 to ground a conceptual service model. In section 4, we apply and elaborate this service model by showing how it can be used to describe and design services from a marketing perspective; for instance, how do we conceptualize needs and wants? Section 5 provides conclusions and directions for future research.

\section{The REA Ontology}

The Resource-Event-Agent (REA) ontology was formulated originally in [19] and has been developed further, e.g. $[13,20,21]$. Its conceptual origins can be traced back to traditional business accounting. REA was originally intended as a basis for accounting information systems and focused on representing increases and decreases of value in an organization. REA has been extended to form a foundation for enterprise information systems architectures [21], and it has also been applied to e-commerce frameworks [13].

The following outline of core REA concepts is slightly adapted by adopting some concepts from [21] and [22] that are further emphasized in [23] and [24]. The main adoption is in the usage of rights. When in the following we say that resources are transferred between agents, we mean that different kinds of rights on resources are transferred. We stick to the conventional value modeling terminology while keeping in mind that by this adoption it is more correct to say that value models capture the distribution of rights among agents.

\subsection{Resources}

The core concepts of the REA ontology are Resource, Event, and Agent (also referred to as Economic Resource, Economic Event and Economic Agent), see Fig. 1. A resource is an object that is viewed as being valuable by some agent. Some concrete 


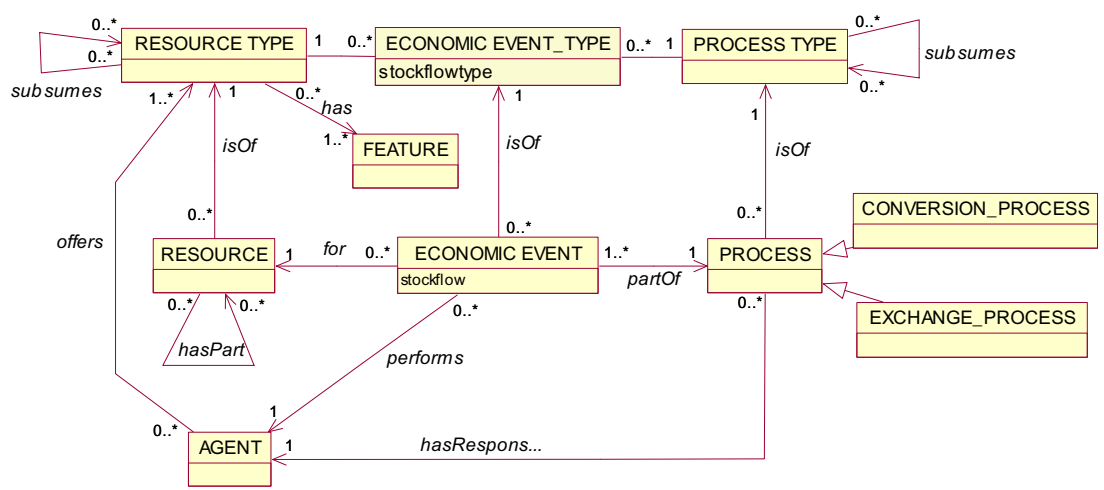

Fig. 1. REA ontology core concepts

examples of resources are books, cars, movies, hair cuts, and medical treatments. However, resources can also be of a more psychological and social nature, such as status, beauty, pleasure, health state, honor, and feeling of safety. To distinguish between these different kinds of resources, we identify two categories of resources, economic resources and internal resources. Intuitively, an economic resource is a resource that can be transferred. More precisely, an economic resource is a resource that can be under the control of an agent, in the sense that the agent may have legal rights on the resource. Analyzing economic resources, we have identified the following categories:

- Goods, which are physical objects, like cars, refrigerators, and cell phones.

- Information, which is data in a certain context, like blueprints, referrals, and customer databases.

- Labor, which is physical or intellectual work done by people.

- Services, which are economic resources that encapsulate other resources and are used for changing, in some respect, another resource. Examples of services are hair cuts and eye treatments.

- Vouchers, which are certificates that can be exchanged for other specific economic resources, e.g. a good or a service. Usually, a voucher can be exchanged only at some pre-specified agent(s). Money can be viewed as the most general form of voucher without any restriction on economic resources and agents.

In addition to economic resources, there are also internal resources that cannot be directly transferred between agents. An internal resource is defined as a resource that is not an economic resource. Some straight-forward examples of internal resources are beauty, health state, honor, and glory. It is not meaningful to talk about legal rights on these resources, neither is it possible to transfer any of these resources from one agent to another. Another example of an internal resource is knowledge. At first sight, it might seem that knowledge is possible to transfer from one agent to another. However, knowledge itself cannot be transferred, but only the information that may be used for producing knowledge, e.g. in the form of a book or a lecture. Resources are often desired by people for their own sake, e.g. someone might desire more knowledge without any intention to use it in a particular way. However, someone else 
might desire knowledge in order to make money through lecturing or other knowledge services, i.e. she uses knowledge as an instrument for producing some other resource. Thus, internal resources can be seen both as ends in themselves and as instruments for other purposes. Economic resources, on the other hand, are only valuable as instruments for producing other resources.

A resource may have properties and associations to other objects, like the nutritional content of a pizza or the number of shops accepting a credit card. Such properties and associations are modeled by means of the class Feature [21].

When modeling resources, there is often a need to distinguish between a class $R e$ source and a class ResourceType, see Fig. 1. A resource type is the abstract classification or definition of a resource. An example of a resource type could be a car model, such as "Volvo V70", while a resource is a specific, concrete car, which can be classified as being of the resource type "Volvo V70". This distinction between two model levels is relevant not only for resources but also for practically any phenomena [25]. The lower level, often called the operational level, models concrete, tangible individuals in a domain. The upper level, often called the knowledge level, models information structures that characterize categories of individuals at the operational level. The Resource type may furthermore model resources on different levels of abstraction and in fig. 1 the relationship between resource types on different levels is captured by means of the association subsumes.

\subsection{Economic Events and Conversion Processes}

As stated in the previous section, resources can be used as instruments to produce or modify other resources. A process that uses some input resources to produce new or modify existing resources is called a conversion process, [Hru06], see the class ConversionProcess in Fig. 1. For example, water and flour can be used as input economic resources in a baking conversion process to produce the output economic resource bread. Another example is an eye treatment (input economic resource) that is used to improve the health state (output internal resource) of a patient. In some cases, a conversion process produces a brand new resource (bread), while in other cases the conversion process modifies an existing resource (health state). In other words, a conversion process can have two different results: a new resource or a modified resource. A conversion process consists of atomic actions called economic events, where each economic event either consumes, uses or produces a resource.

\subsection{Economic Events and Exchange Processes}

An exchange process takes place when two agents exchange resources. To acquire a resource an agent has to give up some other resource. For example, in a goods purchase a buying agent has to give up money in order to receive some goods. The amount of money available to the agent is decreased, while the amount of goods is increased. Conceptually, two economic events are taking place in this exchange process: one where the amount of money is decreased and another where the amount of goods is increased. This combination of economic events is called a duality and is an expression of economic reciprocity - an economic event increasing some resource is always accompanied by an economic event decreasing another resource. A 
corresponding change of availability of resources takes place at the seller's side. Here the amount of money is increased, while the amount of goods is decreased.

\subsection{Processes}

A conversion process consists of economic events that change the features of resources, while an exchange process consists of economic events that change the rights agents hold on resources. However, conversion processes and exchange processes are similar in the sense that they both consist of economic events that increase or decrease the value of resources for an agent. Thus, we generalize ConversionProcess and ExchangeProcess into Process, as shown in Fig. 1. Following [21], we introduce a stockflow attribute on EconomicEvent that shows how the economic event affects a resource; there are five possible stockflows:

- take - the economic event results in an increase of the value of some resource within an exchange process

- give - the economic event results in a decrease of the value of some resource within an exchange process

- produce - the economic event results in an increase of the value of some resource within a conversion process

- $u s e$ - the economic event results in a decrease of the value of some resource within a conversion process

- consume - the economic event results in the consumption of some resource within a conversion process

While the take, give, and produce stockflows are straight-forward to understand, the use and consume stockflows may seem difficult to distinguish as both decrease the value of resources. The difference is that a resource subject to use remains after its use and can be reused, while a resource subject to consumption ceases to exist after its consumption.

Just as for resources, we distinguish between an operational and a knowledge level for processes. In a conversion process, concrete resources are used or consumed to produce or modify other resources, while a conversion process type specifies requirements on resource types that play the roles of inputs and outputs. Furthermore, there is an association subsumes on process types, analogous to the corresponding one on resource types.

\subsection{Agent}

Finishing off this outline of core REA concepts, an Agent is an individual or organization capable of having control over economic resources, and transferring or receiving the control to or from other individuals or organizations [26].

\section{A Conceptual Service Model}

In this section, we analyze the notion of a service starting from a number of definitions and characterizations in the literature of business administration, software engineering 
and service science and engineering. We then identify a number of salient features of services and show how they can be understood and represented using the REA ontology.

There are many definitions of the term "service" in the literature, some representatives being:

W3C: "A service is an abstract resource that represents a capability of performing tasks that represents a coherent functionality from the point of view of provider entities and requester entities. To be used, a service must be realized by a concrete provider agent. A Web service is a software system designed to support interoperable machine-to-machine interaction over a network. It has an interface described in a machine-processable format (specifically WSDL)." [14].

OASIS: "A service is a mechanism to enable access to one or more capabilities, where the access is provided using a prescribed interface and is exercised consistent with constraints and policies as specified by the service description." [11].

WSMO: "A service in contrast is the actual value provided by this invocation. Thereby a Web service might provide different services, such as for example Amazon can be used for acquiring books as well as to find out an ISBN number of a book. A WSMO Web service is a computational entity which is able (by invocation) to achieve a users goal." [15].

Preist: "A service is the provision of something of value, in the context of some domain of application, by one party to another. We need to distinguish between a particular provision of value from the general capability to provide. We refer to the former as a concrete service, and the latter as an abstract service. Hence an abstract service is defined as the capacity to perform something of value, in the context of some domain of application. An agreed service is an abstract service agreed between two parties." [12].

Lusch: "In S-D logic, service is defined as the application of specialized competences (knowledge and skills) for the benefit of another entity, rather than the production of units of output. These benefits are always manifested in the context of the customer, rather than in the production of its offering by the provider. The contextual perspective suggests that what firms provide should not be understood in terms of outputs with value, but rather as resource inputs for a continuing value-creation process." [10].

UN: "Services are heterogeneous outputs produced to order and typically consist of changes in the conditions of the consuming units realized by the activities of producers at the demand of the consumers." [13].

In these definitions, a common view is that a service is an abstraction of activities that once started will achieve some user goal. However, the exact way of defining a service depends on the perspective of a particular source. For example, Preist, UN, and OASIS focus on a business service perspective, while $\mathrm{W} 3 \mathrm{C}$ and WSMO have a web (or software) service perspective.

Drawing on an extensive literature study, [27] argues that there are four main characteristics of services: intangibility, inseparability, heterogeneity, and perishability. Intangibility means that services cannot be seen, felt, or touched in the same concrete way as goods can be sensed. Intangibility is often seen as the critical difference 
between goods and services from which all other differences emerge, [28]. Inseparability is the simultaneous production and consumption of goods. "Whereas goods are first produced, then sold and then consumed, services are first sold, then produced and consumed simultaneously", [27]. Heterogeneity is about the high variability in the performance of services. The quality of a service may vary from provider to provider, from customer to customer, and from time to time. Heterogeneity, however, can also be observed in the production of certain goods and information, such as handicraft objects and newspaper articles. Perishability means that services cannot be saved. If an airline seat is unoccupied, it cannot be saved for future use. However, many kinds of goods are also perishable, such as fresh food.

Based on the above definitions and descriptions of services, it is possible to identify five salient characteristics of services:

1. A service is a resource since it is an object that is considered valuable by agents and that can be transferred from one agent to another.

2. A service is always provided by one agent for the benefit of another agent. An agent will never provide a service to himself, but always to another agent.

3. A service is existence dependent on the processes in which it is produced and consumed, which means that the service exists only when it is consumed and produced. In other words, a service is consumed and produced simultaneously. In contrast to goods and information, a service cannot be stored for later consumption.

4. A service is an intangible and abstract resource in the sense that it encapsulates a set of resources that are provided by one agent to be used by another agent. More precisely, when an agent consumes a service in a process, this means that she uses the resources encapsulated by the service. It should be noted that when an agent acquires a service in an exchange process, she does not get ownership rights on the encapsulated resources, but only use rights.

5. A service is always governed by a policy. This means that when a service is consumed, the resources encapsulated have to be used in compliance with a number of rules formulated in a policy.

Fig. 2 shows how these characteristics of services can be captured using REA notions. The figure shows the REA classes from Fig. 1 in white, while new classes are in grey.

1. We introduce Service as a subclass of Resource as well as ServiceType as a subclass of ResourceType.

2. In order to be able to represent that a service is always provided by one agent to another agent, we make use of the association offers from Agent to ResourceType and consumedBy from Service to Agent. The second association is in fact derivable, as the consumer of a service is the agent that performs the economic event that consumes the service.

3. In order to model that a service is existence dependent on the processes in which it is consumed and produced, we include two associations produces and consumes. These two associations are in fact derivable; a process consumes a service if it contains an economic event with a consume stockflow that is related to that service, and the same holds for production of services. 
4. In order to model the fact that a service is an abstract resource encapsulating other resources, we use an association encapsulates, which is needed on the operational as well as the knowledge level. An example is that a surgery service could encapsulate hospital facilities, laser instruments, surgeon and nurse labour, and anesthesia. Stating that a resource is encapsulated in the service is not equivalent to stating that it is a part of the service. The partOf association is homogenous in the sense that a resource and its parts must be of the same kind, while a service may encapsulate a resource of any kind. For example, a part of a good must be a good, while a service may encapsulate both goods and information as well as other kinds of resources. Furthermore, the partOf association is transitive with respect to ownership rights, while encapsulates is not. For example, if an agent owns some goods, she also owns all its parts, but if she owns a service, she does not own the encapsulated resources.

5. In order to represent the policy governing a service type, the class Policy has been introduced.

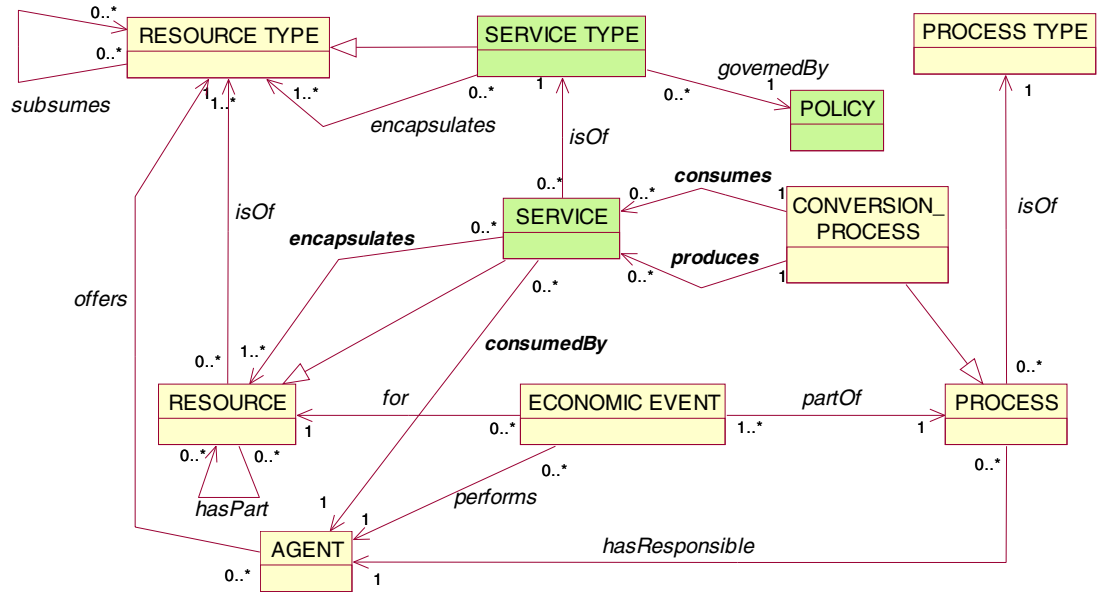

Fig. 2. Conceptual service model with relations to the REA ontology

When describing and advertising a service, it is typically more important to make clear how the service can be used in conversion processes rather than to specify the resources it encapsulates. In other words, it is often immaterial which resources the service encapsulates and sometimes the exact resources to be included when using it can be determined at delivery time. For example, when offering a hair-cut service, the decision whether to use a pair of scissors or a machine can be taken at delivery time. This implies that in describing services using the class ServiceType, the specification can often be at a more abstract level omitting the resource types encapsulated. Using the subsumes association, a more concrete description of a service can be given that also specifies resources encapsulated.

In summary, the conceptual service model (Fig. 2) is based on the REA ontology with primarily the concept of service and its relations added. We have omitted those parts of REA that have no immediate effect on or connection to the service concept, 
such as contracts and commitments. In the following section, we will further elaborate on this model by indicating how common marketing concepts, like needs, wants, and benefits, can be related to it.

\section{Application to Marketing Oriented Service Design}

In this section, we will discuss how the conceptual service model introduced above can be used for describing and designing services based on a marketing perspective. Our starting point will be a small number of well established core concepts in marketing as introduced in [29], in particular needs, wants, demands, and benefits (grey in fig. 3). We will describe these concepts, show how they can be modeled using REA, and suggest a graphical device based on these concepts and the proposed service model that can assist service description and design from a marketing point of view.

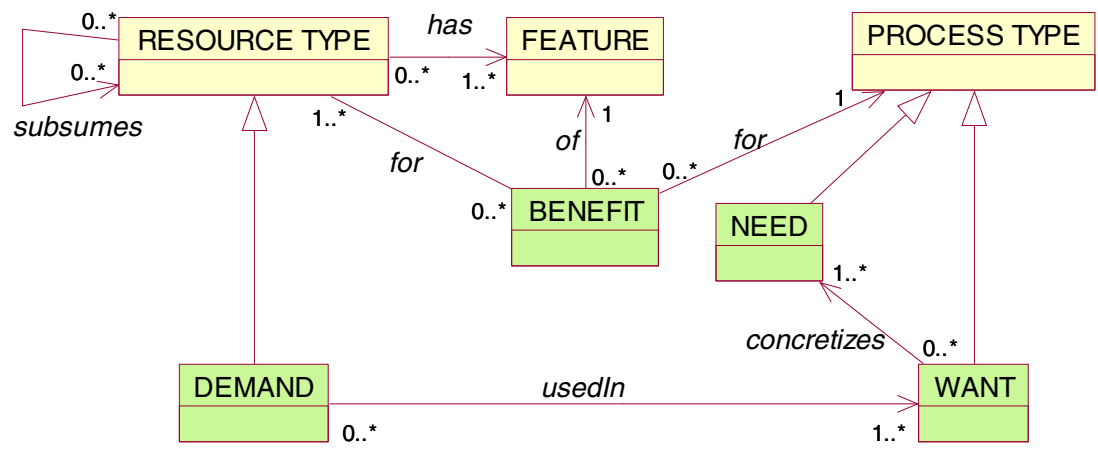

Fig. 3. Conceptual marketing model with relations to the REA ontology

According to [29], needs are basic human requirements, like food, water, rest, and to get shelter. People also have a need to get recreation, entertainment, education as well as other social needs. A well-known framework for classifying and analyzing needs is Maslow's hierarchy of needs, [30], which includes physiological needs, safety needs, and social needs as well as cognitive and aesthetic needs. A need becomes a want when it is directed to resources that can be used to satisfy the need. For example, a person may have a need to reduce his thirst, which can be directed to the want of having a soft drink. A demand is the desire for a particular product that is backed up by the willingness to pay for it. For example, the want of having a soft drink can result in a demand for a Coke, a product offered by a specific supplier. Benefits are properties of products that make them particularly useful for satisfying needs and wants.

It is possible to model needs in several different ways using the REA ontology. A need could be viewed as an internal resource, as a process that is carried out to produce an internal resource, or as an economic resource that is essential for producing some internal resource. In all these cases, the focus is on internal resources as these are objects that have an intrinsic value and are not only means for achieving something else. This is in line with the idea that a need is a basic human requirement 
concerning something desired for its own sake and not as an instrument. We choose here to model a need as an abstract process type that is related only to economic event types with a produce stockflow concerning internal resource types. Thus, a need is modeled as an activity, e.g. "to take care of my eyes". Furthermore, the need is related to its reasons, why the activity should be carried out, in the form of the internal resource types that the process type produces. For example, the need "to take care of my eyes" is related to the internal resource "eye health", as this activity helps to produce or maintain the eye health. However, a need is abstract in the sense that it does not specify what resource types that are requested as input for the activity. We have chosen to model needs as process types as this enables easy and flexible ways of formulating needs, and it also simplifies the modeling of wants as discussed below.

A need can be made more specific and concretized into a want by specifying what resource types that are needed as input for carrying it out. This means to outline a solution for how to satisfy the need. For example, the need "to take care of my eyes" can be concretized into the wants "to have an eye treatment" or "to take medicine". In the first case, the input resource type is a service type "eye treatment" and in the second case a goods type "medicine". Thus, we model a want as a process type that is related to economic event types with both produce and use/consume stockflows. A demand is a supplier specific resource type that is used as input to a want.

When a resource is used in a process, some of its features can be especially useful, beneficial, for that process. For example, the nice taste (feature) of a medicine (good) can be a benefit in a process "to take medicine", in particular for kids. Thus, we define a benefit as a relationship between a feature of a resource type and a process type. As there are many different kinds of benefits, it is helpful to identify a number of benefit categories that can be used to structure and discover benefits.

Table 1. Examples of benefit categories

\begin{tabular}{|l|l|l|l|}
\hline Speed & Reliability & Low cost & Flexibility \\
\hline Customizability & Quality & Security & Safety \\
\hline Convenience & $\ldots$ & & \\
\hline
\end{tabular}

The benefit relationship has been widely explored in management science, e.g. [27, 29, 31] and also in computer science, e.g. [32, 33], but there under different names, like value enhancers or second order values. The consolidated list in Table 1 contains a sample of benefit categories suggested in the literature from those domains. The topic of identifying benefit categories is important as they help in organizing benefits and thereby justify particular processes. However, a deeper investigation of benefit categories is outside the scope of this paper.

Based on the conceptual models in Figs. 2 and 3, we introduce a graphical device that can be used for describing and justifying product and service designs at various levels of abstraction (Figs. 4-6). This graphical device is essentially a set of object diagrams based on the above models, though we use a slightly different notation. The diagrams are in some respects similar to that of [34], but differ in the emphasis on 


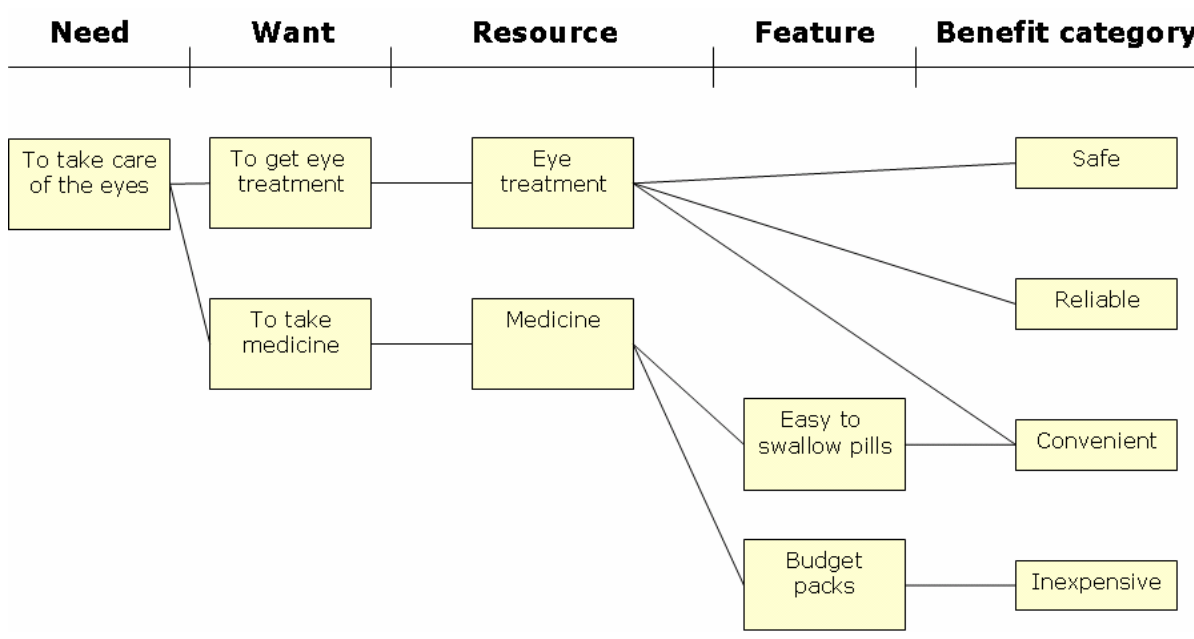

Fig. 4. Object model of a care taking scenario

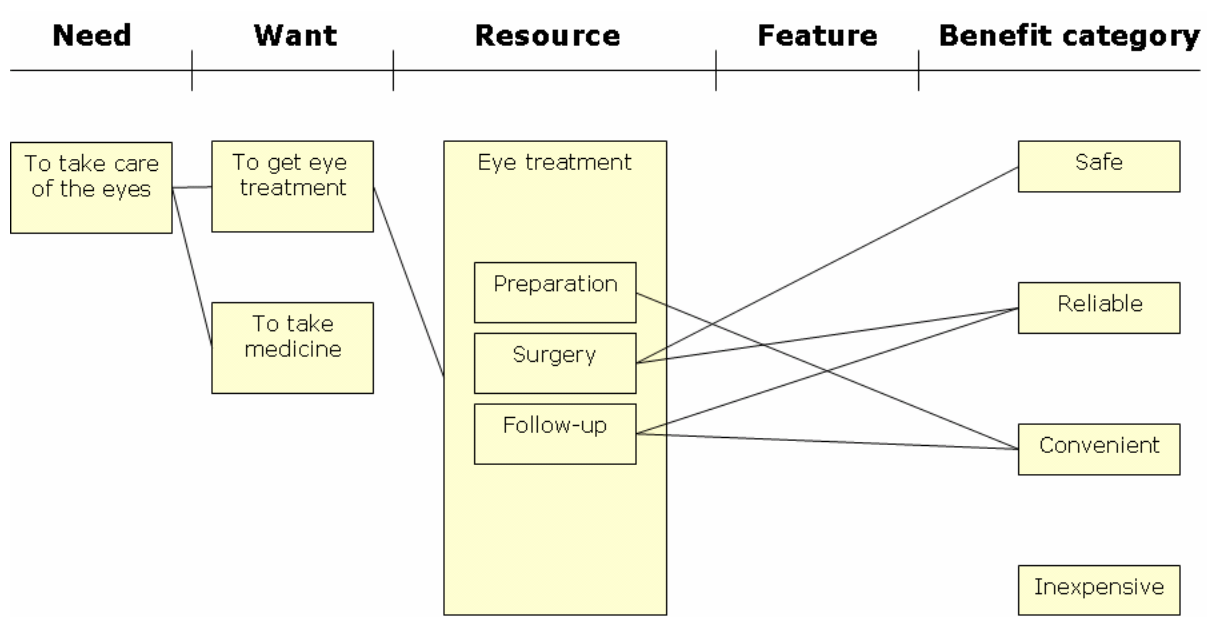

Fig. 5. Expanded object model showing component resources

resources, the introduction of benefit categories, and the omission of offerings. The diagram can be viewed as a table with five columns. The first column contains needs modeled as process types, the second column contains wants concretizing these needs, the third column includes resources used as input in the want processes, the fourth column contains features of these input resources, and the last column is used to specify what kinds of benefit the resources and features bring. An example is shown in Fig. 4, which is about eye health care needs and services.

The diagram in Fig. 4 is at a high level of abstraction displaying services as input resources. However, these services can be exploded on two levels using the partOf and encapsulates associations, respectively. In this way, it becomes possible to show 


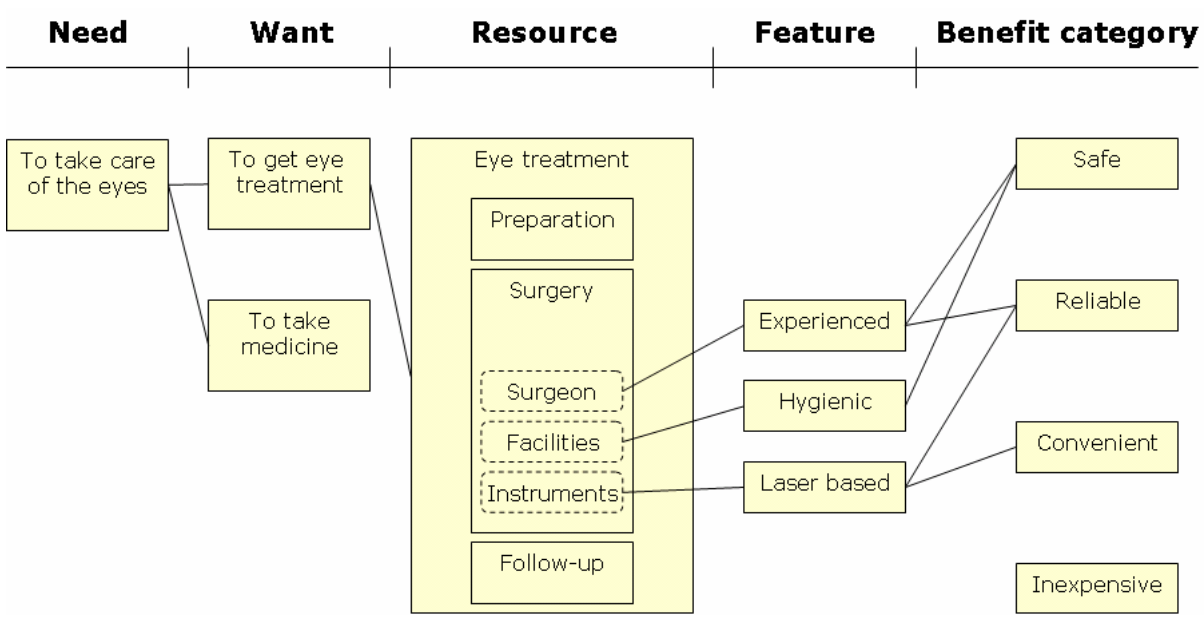

Fig. 6. Expanded object model including features

the subservices that are components of a service as well as the resources used when a service is consumed. An example is given in Figs. 5 and 6 where part $O f$ is shown in square rectangles and encapsulates in rounded rectangles with dotted lines. Fig. 5 shows how the service "Eye treatment" consists of the component services Preparation, Surgery, and Follow-up. Fig. 6 shows the resources encapsulated by the service Surgery: Surgeon, Facilities, and Instruments.

This type of diagram will assist in describing the value and structure of services by showing the wants and needs a service can fulfill and by making explicit the components and benefits of a service. It can be noted that for services it is often difficult to identify their specific benefits as they are abstract and intangible. Instead, only the benefit category can be identified, as in Fig. 5 where the Eye treatment is characterized as safe, reliable, and convenient. However, when showing the resources encapsulated by a service, it becomes possible to identify specific benefits, e.g. the experience of a surgeon in Fig. 6, and their benefit categories.

\section{Concluding Remarks}

The notion of service has proved to be a useful abstraction for understanding how ITresources can be provided for business enterprise but has still to reach its potential as a means for understanding business offerings and collaborations. For enterprise modelling the abstractness, however, contributes to the problem of understanding it as a business concept. This paper has addressed the issue of describing and representing business services. For this purpose, we have introduced a conceptual service model based on value oriented notions, in particular from the comprehensive REA ontology. The model emphasizes that a service is a special case of a resource that it is always provided by one agent to another, that a service is produced and consumed simultaneously, that a service works as an encapsulation of other resources, and that the use of these resources is governed by policies. To illustrate the use of this service model, we 
have also used the REA ontology to analyze basic notions in marketing, like need, want and benefit, and summarized them in a conceptual marketing model. The proposed models can be used to achieve a number of different goals in service design and description:

- Clear and uniform representation and formulation. Modeling services, needs, wants, and benefits by means of REA notions will encourage precise expressions and clarifies the relationships between service and marketing notions. Furthermore, uniformity is supported in the sense that the models assist different designers to formulate themselves in similar ways.

- Traceability. The conceptual marketing model supports traceability by making explicit how services contribute to wants and needs and how features of resources can function as benefits.

- Benefit design. The models can help in identifying benefits of services. A company could start from a product it currently offers and identify its benefits. For each benefit category, the company can then consider whether it should improve its product offering by including new or improved features of the product, which are benefits in that category.

- Support of comprehensive service design. The models can help in designing and visualizing more complete and comprehensive service offerings. A company could start from a product it currently offers and identify all the wants it can be used in. For each want, the company can then determine the other needed input resources and consider whether it would be useful for the company to package these resources and its current product into a new service to be offered.

In the SOA area, there exist several models of services, e.g. $[11,14]$. In contrast to the model proposed here, these models focus on software services including their technical aspects such as message transfers and choreography while disregarding economic value aspects. This paper extends previous work presented in [35] by a more detailed analysis of encapsulation, an explicit grounding on the REA ontology, and a novel application.

There are several different directions for future work on the conceptual service model. One is to extend the model by including more service related aspects, such as service functions, service goals, and details on service policies. The present model includes the core notions of services but needs to be expanded in order to improve the applicability. Another direction is to identify other applications of the model, e.g. on service matching, business process design, and the relationship between real-world services and software services.

\section{References}

1. Gordijn, J., Akkermans, J.M., van Vliet, J.C.: Business Modeling is not Process Modeling. In: Mayr, H.C., Liddle, S.W., Thalheim, B. (eds.) ER Workshops 2000, vol. 1921, pp. 4051. Springer, Heidelberg (2000)

2. Yu, E.: Models for supporting the redesign of organizational work. In: Proc. Conference on Organizational Computing Systems (COOCS 1995), Milpitas, California, USA, pp. 226-236. ACM, New York (1995) 
3. Business Motivation Model release 1.3. The Business Rules Group (2007), http: / / www. businessrulesgroup.org/second_paper/BRG-BMM.pdf

4. Olle, W., Hagelstein, J., Macdonald, I., Rolland, C., Sol, H., van Assche, F., VerrijnStuart, A.: Information Systems Methodologies. A Framework for Understanding. Addison-Wesley, Reading (1988)

5. Sowa, J.F., Zachman, J.A.: Extending and formalizing the frameworkfor information systems architectures. IBM Systems Journal 31(3), 590-616 (1992)

6. IDS Scheer. Enterprise Architectures and ARIS Process Platform, White Papers (Acc. June 30, 2008) (2005), http : / /www . changeware. net / doc/wp_ea.pdf

7. IBM Systems Journal. Service Science, Management and Engineering 47(1) (Acc. March 08, 2008) (2008), http: / / www.research. ibm. com/journal / sj 47-1.html

8. Spohrer, J.: Service Science: The next frontier in service innovation, IBM Corporation (2007), http://www-304.ibm.com/jct09002c/university/scholars/skills/ ssme/spohrer07int.pdf

9. Goldkuhl, G., Röstlinger, A.: Beyond Goods and Services - an Elaborate Product Classification on Pragmatic Grounds. In: Seventh International Research Symposium on Service Quality, QUIS, Karlstad, Sweden, vol. 7 (2000)

10. Lusch, R.F., Vargo, S.L., Wessels, G.: Towards a conceptual foundation for service science: Contributions from service-dominant logic. IBM Systems Journal (January 24, 2008), http: / /www.research.ibm.com/journal/sj/471/lusch.html

11. OASIS. Reference Model for Service Oriented Architecture 1.0 (2006) (Feburary 19, 2008), http: / /www.oasis-open.org/committees/download.php/19679/ soa-rm-cs.pdf

12. Preist, C.: A Conceptual Architecture for Semantic Web Services. In: van Harmelen, F., McIlraith, S.A., Plexousakis, D. (eds.) ISWC 2004, LNCS, vol. 3298, pp. 395-409. Springer, Heidelberg (2004)

13. United Nations Centre for Trade Facilitation and Electronic Business UN/CEFACT Modelling Methodology (UMM) User Guide (Acc. November 2007) (2003), http: / /www . unece.org/cefact/umm/UMM_userguide_220606.pdf

14. W3C. Web Services Architecture W3C Working Group (2004), http://www.w3. orgTRws-arch

15. Roman, D., et al.: Web Service Modeling Ontology. Applied Ontology 1(1) (2005)

16. Colan, M. Service-Oriented Architecture expands the vision of Web services, Part 1. IBM DeveloperWorks (2004) (March 27, 2008),

http: / /www.ibm.com/developerworks/library/ws-soaintro.html

17. Papazoglou, M., van den Heuvel, W.J.A.M.: Service-oriented design and development methodology. Int. Journal of Web Engineering and Technology 2(4), 412-442

18. Chesbrough, H., Spohrer, J.: A Research Manifesto for Service Sciences. Comm. ACM 49(7) (2006)

19. McCarthy, W.E.: The REA Accounting Model: A Generalized Framework for Accounting Systems in a Shared Data Environment. The Accounting Review (1982)

20. Geerts, G., McCarthy, W.: Policy-Level Specifications in REA Enterprise Information Systems. Journal of Information Systems 20(2), 37-63 (2006)

21. Hruby, P.: Model-Driven Design of Software Applications with Business Patterns. Springer, Heidelberg (2006)

22. van der Raadt, B., Gordijn, J., Yu, E.: Exploring Web Services Ideas from a Business Value Perspective. In: Atlee, J., Roland, C. (eds.) Proceedings of the 2005 13th IEEE International Conference on Requirements Engineering (RE 2005), pp. 53-62. IEEE CS, Los Alamitos (2005) 
23. Andersson, B., Bergholz, M., Edirisuriya, A., Ilayperuma, T., Johannesson, P., Gordijn, J., Gregoire, B., Schmitt, M., Dubois, E., Abels, S., Hahn, A., Wangler, B., Weigand, H.: Towards a Reference Ontology for Business Models. In: Embley, D.W., Olive, A., Ram, S. (eds.) ER 2006. LNCS, vol. 4215, pp. 482-496. Springer, Heidelberg (2006)

24. Weigand, H., Johannesson, P., Andersson, B., Bergholtz, M., Edirisuriya, A., Ilayperuma, T.: On the Notion of Value Object. In: Dubois, E., Pohl, K. (eds.) CAiSE 2006. LNCS, vol. 4001, pp. 321-335. Springer, Heidelberg (2006)

25. Fowler, M.: Analysis Patterns - Reusable Object Models. Addison-Wesley, Reading (1996)

26. Gailly, F., Poels, G.: Towards Ontology-driven Information Systems: Redesign and Formalization of the REA Ontology. Working paper. Universiteit Gent, Faculteit Economie en Bedrijfskunde, http: / /www.FEB.UGent.be/fac/research/WP/Papers/wp_07_ 445.pdf2008-03-27

27. Zeithaml, V.A., Parasuraman, A., Berry, L.L.: Problems and Strategies in Services Marketing. Journal of Marketing 49, 33-46 (1985)

28. Bateson, J.E.G.: Do We Need Service Marketing?, in Marketing Consumer Services: New Insights, Marketing Science Institute, Report \#77-115 (December 1977)

29. Kotler, P., Keller, K.L.: Marketing Management, 12th edn. Prentice Hall, Englewood Cliffs (January 1, 2006) ISBN-10: 0131457578, ISBN-13: 978-0131457577

30. Maslow, M.: A Theory of Human Motivation. Psychological Review 50(4), 370-396 (1943)

31. Holbrook, M.B., Hirschman, E.C.: The Experiential Aspects of Consumption: Consumer Fantasies, Feelings, and Fun. The Journal of Consumer Research (1982)

32. Andersson, B., Johannesson, P., Zdravkovic, J.: Aligning goals and services through goal and business modelling. Information Systems and E-Business Management (2008) ISSN:1617-9854, doi:10.1007/s10257-008-0084-2

33. Zarvic, N., Wieringa, R., Daneva, M.: Towards information systems design for value webs. In: Workshop proceedings (BUSITAL 2007) of the 19th Conference on Advanced Information Systems Engineering (CAiSE 2007), vol. 1 (2007) ISBN: 9788251-922456

34. de Kinderen, S., Gordijn, J.: e3 service: An ontological approach for deriving multisupplier IT-service bundles from consumer needs. In: Proc. HICSS (2008), http:// docs.e3value.com/bibtex/pdf/MultisupplierITServiceBundles 200 8.pdf2008-03-27

35. Weigand, H., Johannesson, P., Andersson, B., Bergholtz, M., Edirisuriya, A., Ilayperuma, T., Zdravkovic, J.: Value-based Service Design Based On A General Service Architecture. In: Proc. BUSITAL 2008, Montpellier, France (2008) 